
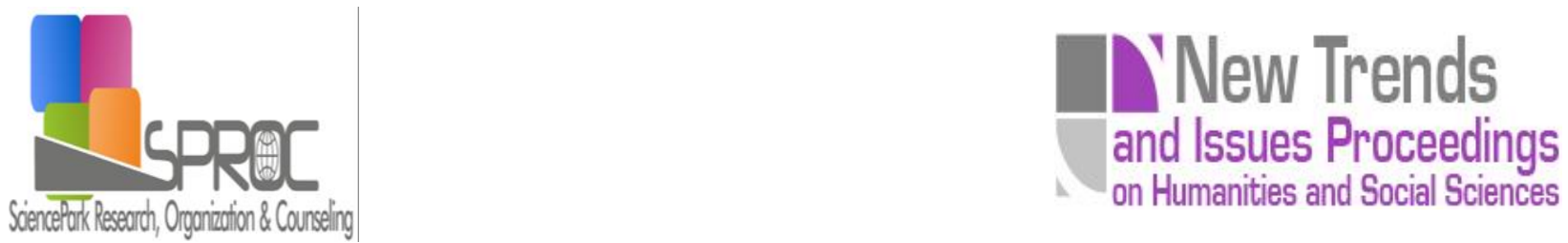

\title{
Students' interest for sport and recreation at Goce Delcev University - Stip, depending the selected Faculty
}

Popeska Biljana ${ }^{*}$

Barbareev Kiril

Emilija Janevik - Ivanovska ${ }^{c}$

Snezana Jovanova - Mitkovska ${ }^{d}$

Suggested Citation:

New Trends and Issues

Proceedings on Humanities and Social Sciences.

Abstract 
New Trends and Issues Proceedings on Humanities and Social Sciences.

1. Introduction 
New Trends and Issues Proceedings on Humanities and Social Sciences. 
2. Methods

3. Results 
New Trends and Issues Proceedings on Humanities and Social Sciences. 


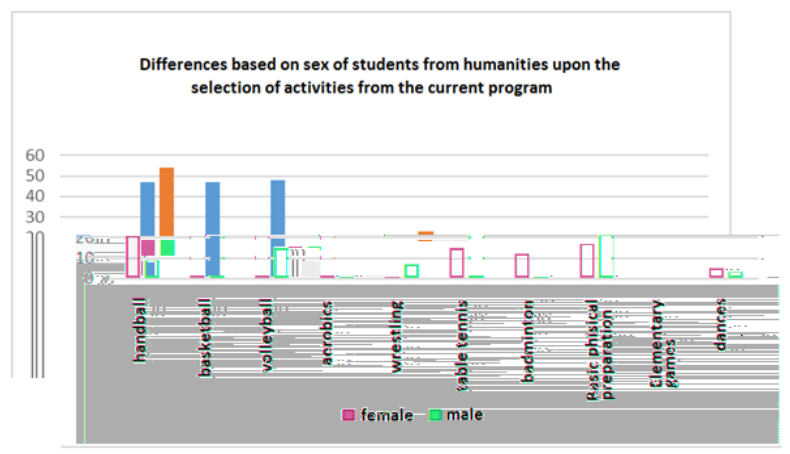

Figure 1. Differences by sex in natural $\&$ technical sciences

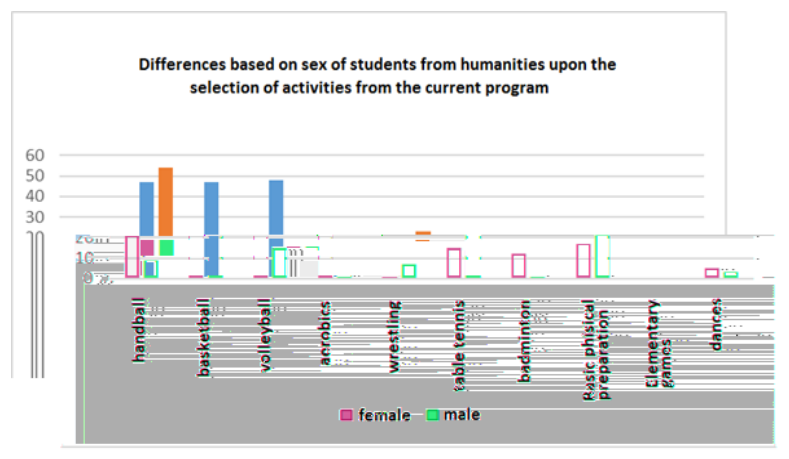

Figure 2. Differences by sex in humanities

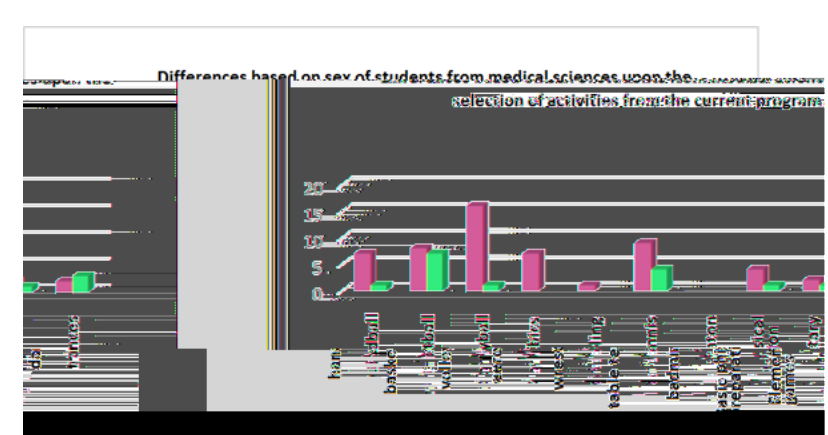

Figure 3. Differences by sex in medicine sciences

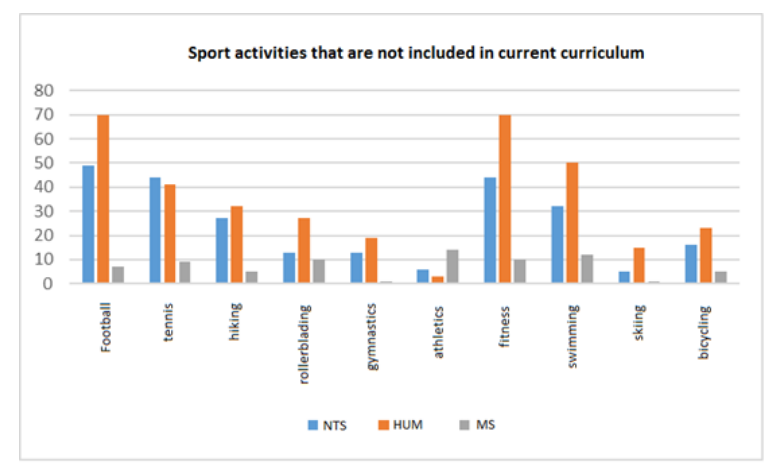

Figure 4. Differences in activities not included in current curriculum 


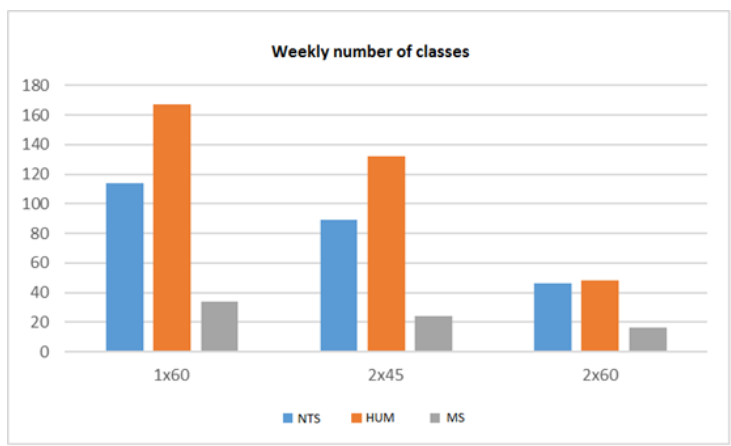

Figure 5. Differences upon weekly number of classes

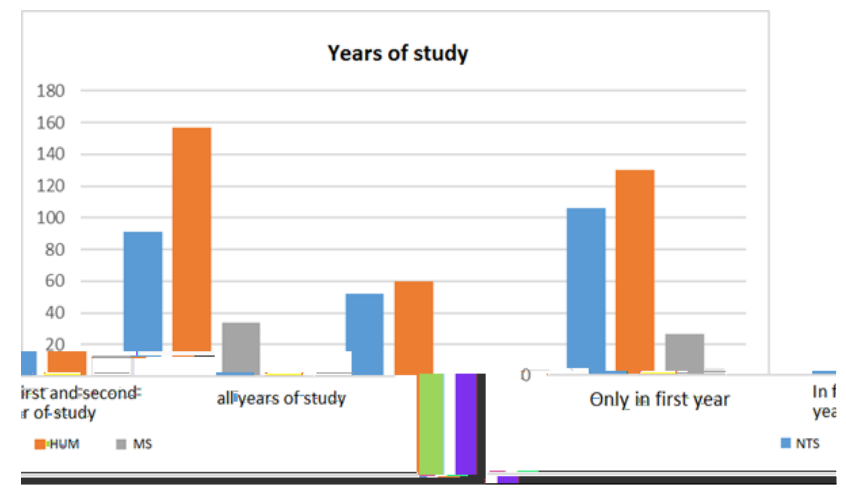

Figure 6. Differences upon year of study 


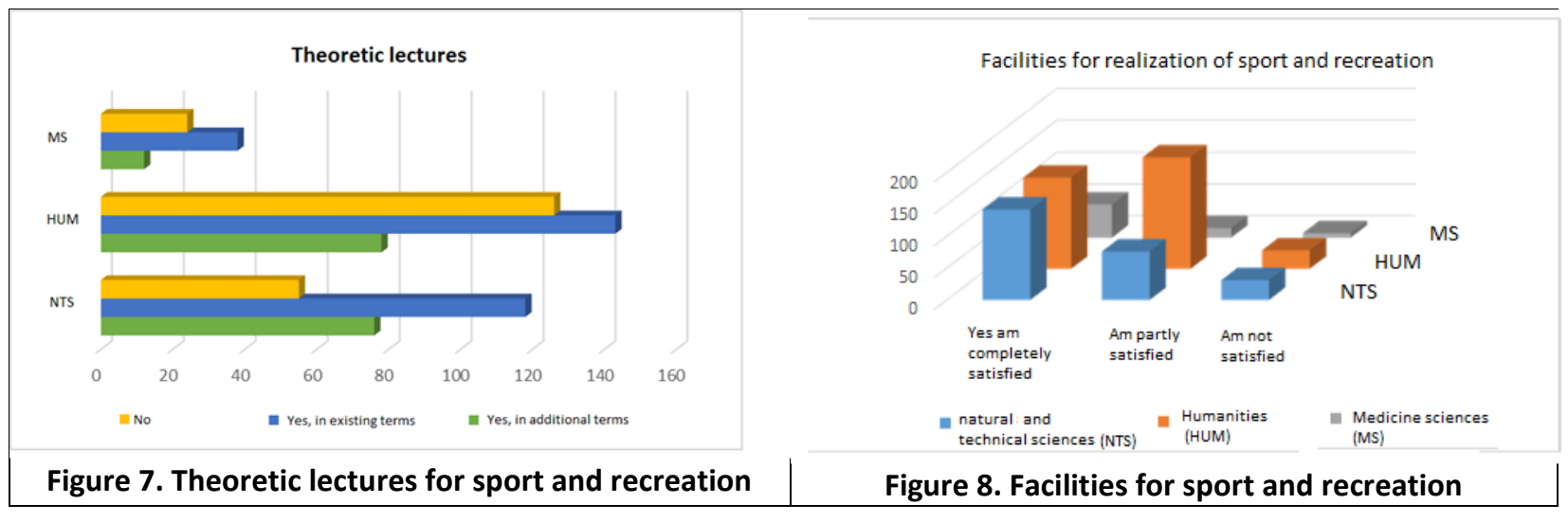

4. Discussion and conclusion 
New Trends and Issues Proceedings on Humanities and Social Sciences. 
New Trends and Issues Proceedings on Humanities and Social Sciences. 
New Trends and Issues Proceedings on Humanities and Social Sciences. 


\section{References}

\section{Kinesiology 37}

\section{R.Q.E.S, 67}

College Health, 53

\section{Journal of American}

Journal of American College Health, 61

Science \& Sport, 1

Life span motor development

Physical Activity Review, 2

Human Biology, 13

American Journal of

Growth, maturation and physical activity

Odgojne znanosti, 10

Health", Tuzla

Second International Conference "Sport \&

Human Kinetics, 27

Journal of 
New Trends and Issues Proceedings on Humanities and Social Sciences.

the Proceeding book of VI International Balkan Congress for Education and Science: the modern society and education

Am J Prev Med, 15 